\title{
A Review of Some Recent Studies on Buoyancy Driven Flows in an Urban Environment
}

\author{
Bodhisatta Hajra \\ Department of Mechanical Engineering, The University of Hong Kong, Pokfulam Road, Hong Kong \\ Correspondence should be addressed to Bodhisatta Hajra; hajra.bodhisatta@gmail.com
}

Received 28 June 2014; Revised 7 September 2014; Accepted 8 September 2014; Published 25 September 2014

Academic Editor: Ilias Mavroidis

Copyright (C) 2014 Bodhisatta Hajra. This is an open access article distributed under the Creative Commons Attribution License, which permits unrestricted use, distribution, and reproduction in any medium, provided the original work is properly cited.

This paper reviews some recent studies (after 2000) pertaining to buoyancy driven flows in nature and thier use in reducing air pollution levels in a city (city ventilation). Natural convection flows occur due to the heating and cooling of various urban surfaces (e.g., mountain slopes), leading to upslope and downslope flows. Such flows can have a significant effect on city ventilation which has been the subject of study in the recent times due to increased pollution levels in a city. A major portion of the research reviewed here consists of natural convection flows occurring along mountain slopes, with a few studies devoted to flows along building walls. The studies discussed here primarily include field measurements and computational fluid dynamics (CFD) models. This review shows that for densely populated cities with high pollution levels, natural convection flows (mountain slope or building walls) can significantly aid the dispersion of pollutants. Additional studies in this area using CFD and water channel measurements can explain the physical processes involved in such flows and help improve CFD modelling. Future research should focus on a complete understanding of the mechanisms of buoyancy flows in nature and developing design guidelines for better planning of cities.

\section{Introduction}

Global air pollution has been a subject of study for several decades. For instance, global warming has caused the melting of ice in the west Antarctic region, thereby increasing the sealevels by several centimetres [1]. However, pollution levels within a city may increase only due to the surrounding topography and local environmental conditions. For example, the London smog in 1952 consisted of large amounts of dusty fumes from nearby factories causing poor visibility and resulting in the deaths of several people during the time [2]. Lack of available land and increased population have led to the construction of high density and high rise buildings in many cities like New York and Hong Kong, thereby increasing city pollution. This situation has been aptly described by Fernando [3] as "The future of humankind is sure to evolve in large urban areas that proffer the highest quality of life. Accelerated growth, however, has overstressed some urban environments, thus calling for sound planning tools for sustainable growth. In this context, of cardinal importance is the prediction of the urban atmosphere (i.e., key meteorological variables and turbulence) and air-quality indicators (e.g., pollutant levels, comfort index)." One of the key issues with urban megacities like Hong Kong is their geographic location and complex topography. These cities are surrounded by mountains and skyscrapers, where wind penetration is greatly reduced causing accumulation of pollutants [4]. Furthermore, during low wind speeds the buoyancy driven flows caused by heating and cooling of surfaces (mountain slopes and building walls) can greatly help disperse these pollutants $[5,6]$. Another problem associated with city level pollution is the urban heat island (UHI) effect, which causes an increase in urban air temperatures as opposed to the surrounding rural region [7-9]. Recent studies indicate that buoyancy driven flows (along mountains and building walls) can help reduce urban air pollution levels and improve the thermal environment in a city. Based on detailed water tank measurements, Reuten et al. [10] stated "Upslope flows are a crucial mechanism in the transport of air pollutants in complex terrain, both as separate flow systems and as part of other thermally driven flows."

Urban ventilation studies have been carried out through field measurements, CFD, and analytical methods. A wellknown field study on the dispersion of tracers on nocturnal drainage flows was carried out under the Atmospheric 
Studies in Complex Terrain (ASCOT) program (see [11] for details) in the Brush Creek valley in Western Colorado, USA. According to [12], the upslope flows generated immediately after sunrise aided in the dispersion of the tracers in the ASCOT study. Similarly, a CFD study on buoyancy driven flows along building walls of a street canyon was carried out by [13], and they found that the ratio of building height to street width played a major role in changing the air and pollutant flow characteristics in the street canyon. Buoyancy driven flows along building walls and mountain slopes were quantified by using the Air Changes per Hour $(\mathrm{ACH})$ concept by [14]. Their study which was primarily based on air temperature measurements using a thermal camera showed that the contribution of building wall flows was twice as high as mountain slope flows due to greater surface area of buildings than in mountains. More recently, CFD simulations to assess city ventilation using the age of air and $\mathrm{ACH}$ concept were carried out. It was found that for buildings taller than $100 \mathrm{~m}$, buoyancy driven flow along building walls is sufficiently high and even comparable to that produced by mountain slope flows [15].

This review focuses on some important recent studies (after 2000) on the application of mountain slope and building wall flows on urban ventilation. A great majority of the studies reviewed in this paper are about mountain slope flows with only a small portion of literature on building wall flows, since most of the studies in the past have considered air pollution in a city primarily due to buoyancy flows along a mountain as opposed to building walls. Only more recent studies (e.g., [16]) have shown that considering flows along building walls is equally important since building surfaces are a major contributor to buoyancy flows, particularly in cities like Hong Kong. Therefore, the present review presents some of the major urban buoyancy flow studies in the recent times and stresses the need to carry out additional buoyancy flow studies on building walls.

Initially, a brief discussion on the mechanism of buoyancy driven flow along vertical plates and mountain slopes is presented (Section 2), followed by the description of field measurements (Section 3) and analytical models (Section 4). Thereafter, CFD simulations (Section 5) and discussions on some key topics (Section 6) are presented. Future developments that are likely to occur (Section 7), followed by conclusions from this review (Section 8), form the concluding parts of this paper.

\section{Buoyancy Driven Flows}

According to Jaluria [17], some of the examples of natural convection flows include, "buoyant flow arising from heat or material rejection to the atmosphere, heating and cooling of rooms and buildings, recirculating flow driven by temperature and salinity differences in oceans." Unlike forced convection flows, natural convection flows are generally associated with a difference in density, which is caused by differences in temperature. In fact, plenty of types of literature exist on natural convection flows over a vertical plate [18]. For instance, Eckert and Jackson derived a formula for heat transfer coefficient for Grashof numbers in the range of $10^{10}$ to $10^{12}$ for a vertical flat plate, for aerospace engineering applications [19]. However, the focus of this paper is on natural convection flows occurring in nature (along building walls and mountain slopes) and how they aid the dispersion of pollutants within a city consisting of closely-spaced, high rise buildings. There is more literature on mountain slope flows and less on building wall flows because the latter has been investigated more recently for UHI issues.

2.1. Buoyancy Driven Flows along Mountains. Plenty of types of literature exist on the buoyancy driven flows along mountain slopes [20], and therefore, only a brief description of the physics of these flows is mentioned here. Figure 1 shows the nature of the winds that develop along mountain slopes [21]. The wind velocity profiles generally tend to be zero closer to the surface owing to friction and gradually increase to about $1-4 \mathrm{~m} / \mathrm{s}$, at a height of about $15 \mathrm{~m}$ during the night (Figure 1(a)). However, the direction is reversed during the day time (Figure 1(b)) and the magnitude of the maximum wind velocity is about $1-5 \mathrm{~m} / \mathrm{s}$, occurring at a height of about $10-50 \mathrm{~m}$. In fact, the depth of the wind profile extends up to $100 \mathrm{~m}$ during the night, as opposed to $200 \mathrm{~m}$ during the day.

Diurnal mountain wind systems have been studied by many researchers in the past $[22,23]$. The momentum equation, energy equation, and continuity equations, by incorporating the Boussinesq's assumption (neglecting the density in the continuity equation) are solved numerically. Zardi and Whiteman [21] state that "A fundamental obstacle to rapid progress in mountain meteorology is that there are almost infinitely many possible terrain configurations. So, any field measurement or numerical experiment that is valid for a specific situation does not automatically have greater significance beyond that case."

This statement aptly describes the problems faced by most CFD modellers and city planners (described later), involved in improving thermal and wind conditions in cities located amidst mountains.

2.2. Buoyancy Driven Flow along a Vertical Plate. Analogous to mountain slope flows is the buoyancy driven flow along a vertical plate (Figure 2). Natural convection flows over a flat vertical surface develop due to the differences in density, induced by temperature changes. For instance, when the wall temperature $\left(T_{W}\right)$ is higher than the ambient air temperature $\left(T_{\infty}\right)$, the warmer air close to the wall rises and the air surrounding it gets entrained (Figure 2(a)), resulting in a net upward flow, whilst the opposite occurs when $T_{W}<T_{\infty}$. At a given height the velocity of flow tends to increase up to a certain point, before reducing to zero, whilst the temperature reduces from higher values to zero gradually away from the wall (Figure 2(b)). These flows are described by several nondimensional numbers, such as Grashof number (ratio of buoyancy to viscous forces), Rayleigh number (product of Grashof and Prandtl numbers), and Nusselt number (ratio of convective to conductive heat transfer coefficients). There are many approximate methods available to estimate the velocity 


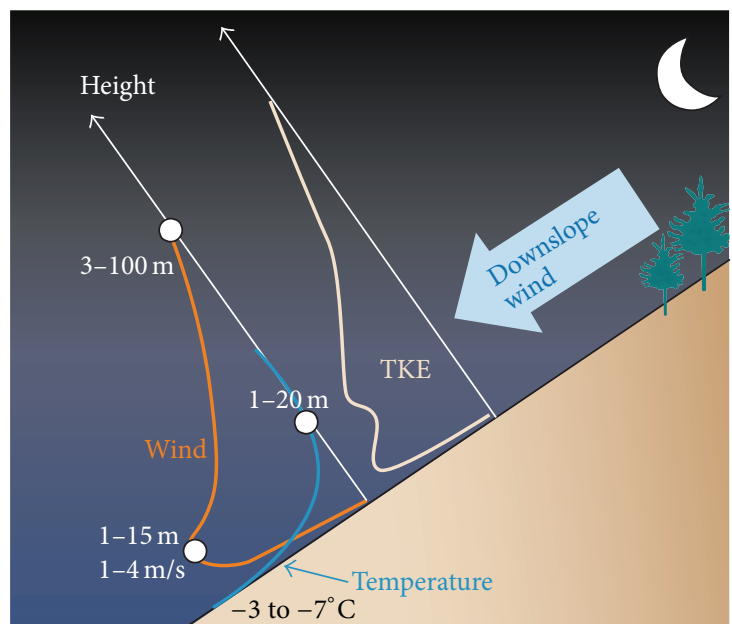

(a)

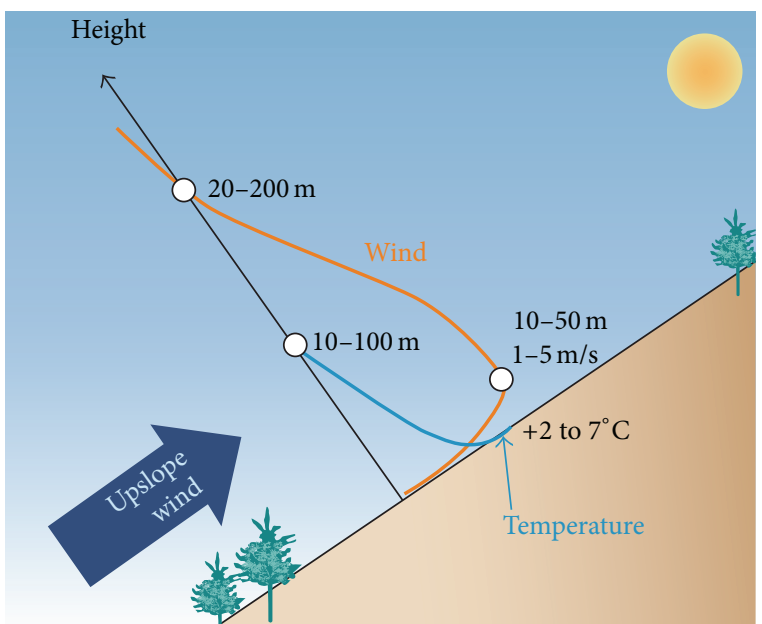

(b)

Figure 1: Mountain wind system: (a) downslope winds; (b) upslope winds (from [21]).

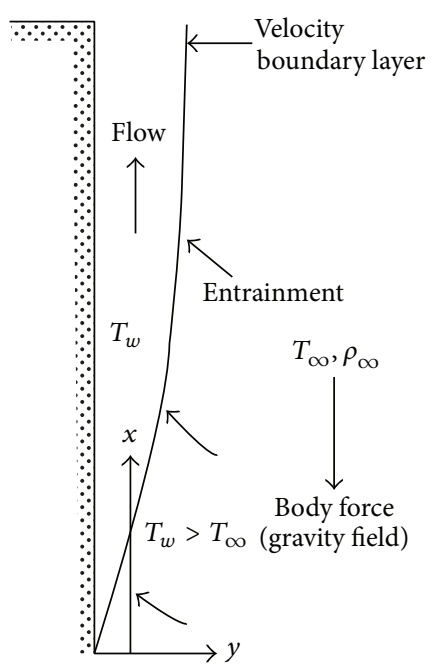

(a)

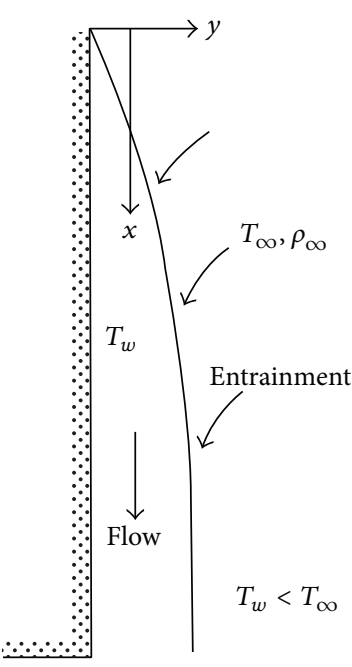

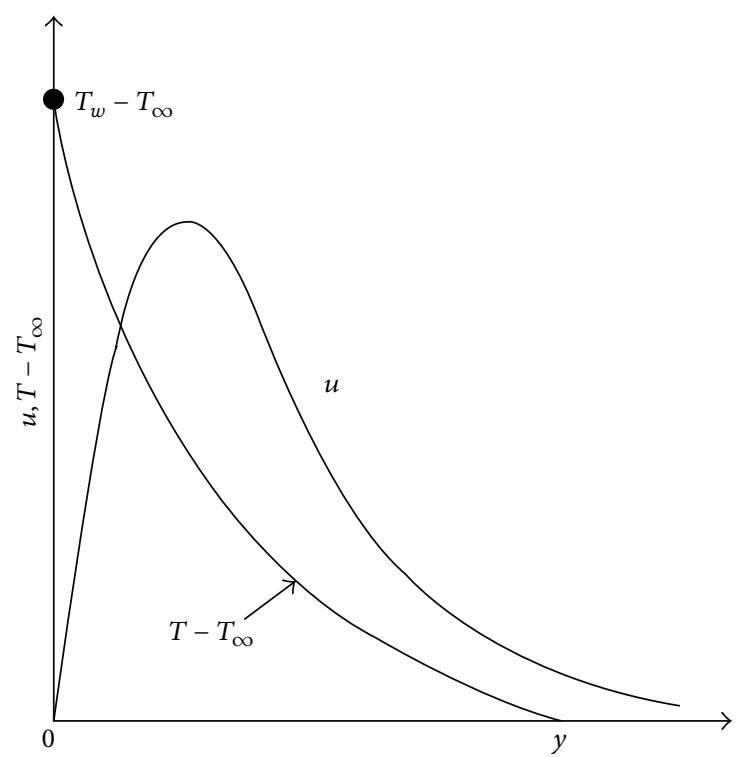

(b)

FIGURE 2: Natural convection over a flat vertical surface: (a) velocity boundary layer; (b) velocity and temperature profiles (from [17]).

and temperature distributions [24], although the application of these techniques for geophysical flows is not fully validated.

Detailed reviews on natural convection flows for vertical and inclined surfaces can also be found from $[25,26]$. Buoyancy flows along a building wall can be considered equivalent to flows along a vertical plate with high Rayleigh number. Although there are studies on measurement of building wall surface temperatures (e.g., [6]), detailed studies on the thermal boundary layer along a building wall must be carried out in future. In fact, an excellent review of natural convective heat transfer coefficients on horizontal and vertical surfaces and their application to buildings is provided in Khalifa [27].

\section{Field Studies on Buoyancy Driven Flows in the Urban Environment}

There are quite a few studies on buoyancy flow measurements in nature, with most of them focused on mountain slope winds and very few on building walls. Only a few are described here, with a more detailed list available in Table 1.

3.1. Atmospheric Studies in Complex Terrain (ASCOT), Colorado, USA. One of the earliest studies on the application of mountain slope flows on the dispersion of pollutants in a valley was carried out in western Colorado, USA, under the ASCOT program (see [12] for details). Perfluorocarbon 
TABLE 1: Various physical modelling studies of buoyancy driven urban flows (2000 and later).

\begin{tabular}{|c|c|c|}
\hline Study type and name & Year* and Reference & Characteristic features \\
\hline $\begin{array}{l}\text { Field study: Vertical Transport } \\
\text { and Mixing (VTMX), Salt Lake, } \\
\text { USA }\end{array}$ & 2000; [29] & $\begin{array}{l}\text { Experiments to assess vertical transport and mixing of various parameters for } \\
\text { mountain slope flows (e.g. heat, air pollution, etc.) }\end{array}$ \\
\hline Field study: URBAN 2000 & 2000; [74] & $\begin{array}{l}\text { (i) Conducted simultaneously with the VTMX study in Salt,Lake, USA. } \\
\text { (ii) Assess tracer dispersion in street canyons due to synoptic and thermally } \\
\text { driven winds (part of the data from URBAN } 2000 \text { was also used for the } \\
\text { VTMX study). }\end{array}$ \\
\hline $\begin{array}{l}\text { Field study in Lower Fraser } \\
\text { valley, British Columbia, } \\
\text { Canada, }\end{array}$ & 2001; [30] & $\begin{array}{l}\text { (i) Water channel measurements were also performed for some cases. } \\
\text { (ii) Return flows that opposed upslope flows were observed. }\end{array}$ \\
\hline $\begin{array}{l}\text { Field study at PICO-NARE } \\
\text { observatory on Pico mountains, } \\
\text { Azores island, North Atlantic } \\
\text { Ocean }\end{array}$ & $2004 ;[75]$ & $\begin{array}{l}\text { (i) Study of buoyancy driven flows and their influence on mountain top } \\
\text { observatories during low synoptic winds. } \\
\text { (ii) Isoprene concentrations (generated from vegetation at the bottom) on the } \\
\text { mountain top reduced due to upslope flows. }\end{array}$ \\
\hline $\begin{array}{l}\text { Field study at } \\
\text { Moravian-Silesian Beskydy } \\
\text { Mountains, Czech Republic }\end{array}$ & $2004 ;[76]$ & $\begin{array}{l}\text { (i) Night time slope flows over a mountain with a dense forest at the foot of } \\
\text { the hill were studied. } \\
\text { (ii) Katabatic flows measured using sonic anemometers, with flow reversal } \\
\text { (similar to [28]), were observed. }\end{array}$ \\
\hline $\begin{array}{l}\text { ADVEX field study, Bolzano, } \\
\text { Italy }\end{array}$ & 2005; [77] & $\begin{array}{l}\text { (i) Study was carried out in a mountainous terrain surrounded by forests at } \\
\text { the bottom; measurements were carried out using sonic anemometer (wind) } \\
\text { and infrared gas analyzer }\left(\mathrm{CO}_{2} \text { and } \mathrm{H}_{2} \mathrm{O}\right) \text {. } \\
\text { (ii) Synoptic winds above the canopy affected the classical slope wind } \\
\text { phenomenon (upslope in daytime and downslope at night) significantly. }\end{array}$ \\
\hline $\begin{array}{l}\text { Field study: Meteor Crater } \\
\text { Experiment (METCRAX), } \\
\text { Winslow, Northern Arizona, } \\
\text { USA }\end{array}$ & 2006; [78] & $\begin{array}{l}\text { (i) SODAR, Radar wind profiler used for the measurements of downslope } \\
\text { flows. } \\
\text { (ii) The flows were not influenced by soil moisture and surface roughness. }\end{array}$ \\
\hline $\begin{array}{l}\text { Field study: Transition flow } \\
\text { experiment (TRANSFLEX), } \\
\text { Phoenix, USA }\end{array}$ & 2006; [34] & $\begin{array}{l}\text { (i) Study of transition mechanism in mountain slope flows (flow reversal from } \\
\text { upslope to downslope). } \\
\text { (ii) Main focus was to assess pollutant concentrations in two of the sites in } \\
\text { Phoenix, USA. }\end{array}$ \\
\hline $\begin{array}{l}\text { Field study: Stable Atmospheric } \\
\text { Boundary Layer Experiment in } \\
\text { Spain (SABLES), Valladolid, } \\
\text { Spain }\end{array}$ & $2006 ;[36]$ & $\begin{array}{l}\text { (i) Study of katabatic winds due to shallow slopes and their effect in reducing } \\
\text { pollution levels. } \\
\text { (ii) Use of wind vanes, tethered balloons, and microbarometers to measure } \\
\text { meteorological variables, stability, and turbulent parameters. }\end{array}$ \\
\hline $\begin{array}{l}\text { Water channel measurements of } \\
\text { upslope flows over an inclined } \\
\text { surface, USA }\end{array}$ & 2007; [43] & $\begin{array}{l}\text { (i) Water channel measurements of upslope flows on an inclined surface were } \\
\text { conducted. } \\
\text { (ii) Relationship between Prandtl number and slope flows were developed, } \\
\text { besides a critical slope angle beyond which the flow sustains. }\end{array}$ \\
\hline $\begin{array}{l}\text { Field study of buoyancy flows in } \\
\text { a street canyon at COSMO, } \\
\text { Japan }\end{array}$ & $\begin{array}{l}2008 ;[16] \\
2010 ;[6]\end{array}$ & $\begin{array}{l}\text { (i) Studies on buoyancy driven flows along building walls of a street canyon } \\
\text { were carried out. } \\
\text { (ii) Height and spacing between buildings were found to be major factors } \\
\text { affecting the flow. }\end{array}$ \\
\hline $\begin{array}{l}\text { Field studies at The University } \\
\text { of Hong Kong, SAR China }\end{array}$ & $2008 ;[14]$ & $\begin{array}{l}\text { (i) Use of infrared camera to assess surface temperatures. } \\
\text { (ii) Study of both slope and wall flows and their influence on city ventilation. } \\
\text { (iii) Use of air changes per hour concept to quantify city ventilation. }\end{array}$ \\
\hline $\begin{array}{l}\text { Wind tunnel study of buoyancy } \\
\text { driven flows in a street canyon, } \\
\text { ETH, Zurich, Switzerland }\end{array}$ & 2012; [79] & $\begin{array}{l}\text { Heating of building walls and ground surface induces two vortices within the } \\
\text { street canyon and their positions change for different windward wall } \\
\text { temperatures. }\end{array}$ \\
\hline
\end{tabular}

${ }^{*}$ Refers to the year in which the experiments were performed.

tracers were released in the valley and its dispersion under nocturnal conditions was studied (see Figure 3 ). It may be mentioned that although this review primarily covers the progress following 2000, this particular study carried out in late eighties is of great significance to mountain slope flow, and, hence, described here. The experiments consisted of releasing the tracers from midnight to early morning, and later these tracers were sampled using about 90 surface samplers. Additionally, some air crafts flying at a height of $1980 \mathrm{~m}$ were also utilised to collect the samples [28]. From 


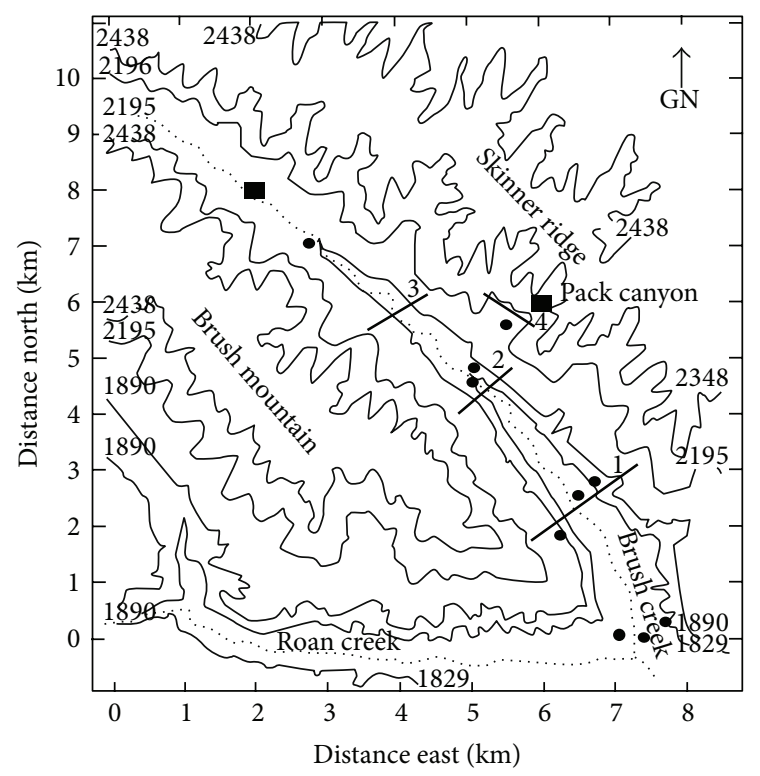

FIgURE 3: Map of the Brush Creek Valley showing the tracer release sites (squares) and the locations of the vertical profile samplers (circles). The thick straight lines denote the positions of the surface sampling arcs (from [12]).

the results the authors concluded that the ventilation of the tracers out of the valley started early in the morning after sunrise, when upslope flows gradually start to dominate.

Additionally, this study showed that the solar intensity, location of the tracer, and ambient meteorology played a major role in the ventilation process. This is one of the most important field studies on estimating the effectiveness of slope winds in ventilating a valley.

It is worth noting that although this study was carried out in the eighties, it has a lot of significance today, since global air pollution has gone up and there is plenty of human settlement along valleys/areas located at the foot of the mountains. This makes it even more important to utilise buoyancy driven winds to reduce pollution levels, especially in the absence of synoptic winds.

3.2. Vertical Transport and Mixing (VTMX), Salt Lake Valley, USA. A major field campaign titled VTMX, sponsored by the US Department of Energy through their Environmental Meteorology program took place in October 2000 in Salt lake valley, USA [29]. The key goals of this field study were to assess the vertical mixing and transport of various parameters, such as heat, air pollution, and momentum in the Salt Lake Valley, and formation of cold pools. Furthermore, studying the effect of nocturnal stability on air pollution concentrations in the valley and how this could affect an urban area located at the foot of the mountain was also a part of the investigation. A number of instruments including SODARS and LIDARS (wind velocity and direction), Radio Acoustic Sounding System (temperature), and tethered balloons (wind velocity, temperature, and humidity), were deployed. The authors reported "a complicated pattern of

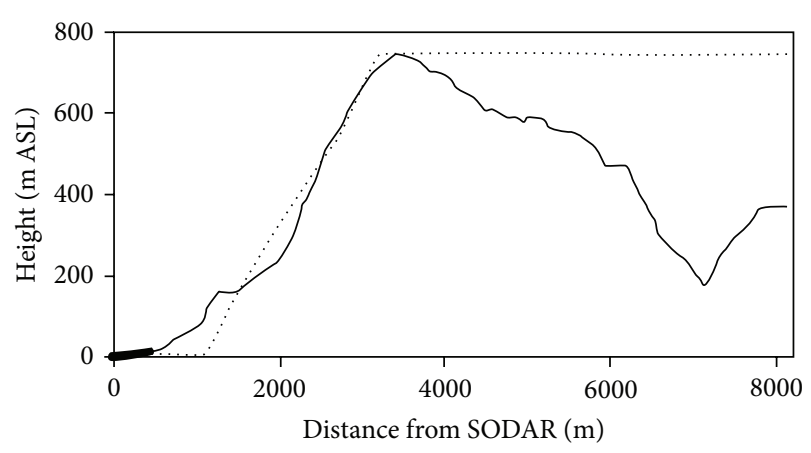

FIGURE 4: Vertical cross-section of the slope; the dashed line is a simplified topography that includes a $19^{\circ}$ angle reaching up to a plateau at $780 \mathrm{~m}$ above the SODAR site, which was $6 \mathrm{~m}$ above sea level (from [28]).

local flows influenced by lake effects, heating and cooling of the valley and the nearby mountains, and interactions with synoptic systems." The idea behind this field study was to incorporate the results of this study in numerical models to better simulate the physical processes involved in mountain flows. Most previous studies including the ASCOT study were mainly focused on understanding the physics behind slope flows. However, the VTMX study also utilised their data for numerical simulations and theoretical model development.

3.3. Upslope Flows in Lower Fraser Valley, British Columbia, Canada. Reuten and his associates [30] carried out field measurements along the slopes of the Lower Fraser Valley in British Columbia, Canada (Figure 4). According to Reuten et al. [30], "The Lower Fraser Valley is nearly flat, mostly below $100 \mathrm{~m}$ above sea level, and has an approximately triangular shape narrowing from about $100 \mathrm{~km}$ width at the Strait of Georgia in the west to about $2 \mathrm{~km}$ approximately $90 \mathrm{~km}$ inland to the east. It is bounded by the Coast Mountain Ranges to the north and the Cascade Ranges to the south-east, which have heights of about $2000 \mathrm{~m}$ and $1000 \mathrm{~m}$ above mean sea level (m.s.l.), respectively." The instruments used for measurement included a Doppler SODAR for measuring wind speeds on the slopes; besides a scanning LIDAR system and a tethersonde were used to measure specific humidity, wind speed and direction, temperature and particulate matter. Their field measurements focused on upslope (anabatic) flows, as opposed to most previous studies that were mostly focused on ventilating a city due to katabatic (downslope) winds. Reuten and his associates showed, from their study, that upslope flows helped reduce pollutant concentrations by dispersing them into the atmosphere, besides the existence of a strong "return flow" due to synoptic winds opposing the upslope flows.

This was an interesting observation, which was not made in any of the earlier field measurements on mountain slope flows. The field measurements were later simulated using water channel measurements by Reuten et al. [10] who reported that "Non-dimensional boundary-layer depths near the base of slope in atmosphere and water tank agree within the measurement uncertainties of the field observations (20\%)." 
3.4. Measurements of Urban Thermal Environment in Tokyo, Japan. Buoyancy driven flows are related to urban thermal environment and due to high levels of pollution in Tokyo, a field measurement was conducted by Ooka and his associates at the University of Tokyo [31] to asses wind velocity, temperature (surface and air), and humidity. This data was used to develop a model that can take account of urban convection flows to assess the thermal environment in a densely packed city environment. Additionally, the model could be incorporated within any existing air pollution dispersion model in order to predict precise urban air quality information. In fact, Ooka et al. [32] also used the results from this study to develop a multiobjective genetic algorithm to assess the outdoor thermal environment, besides researching on the effect of tree plantation on mitigating UHI effects. Some of the key aspects of the studies conducted in Tokyo are the assessment of humidity in addition to air velocity and surface temperature measurements. Additionally, the impact on human comfort (pedestrian comfort) due to UHI effects was also part of these studies, while most other studies on urban buoyancy flows were mostly focused on the physical processes involved in these flows. Wind and thermal environments at the pedestrian level are closely related to buoyancy driven flows through urban surfaces. More recently, CFD simulations of these flows using previous field measurements are gradually being used to develop computational modelling as discussed in detail by Mochida and Lun [33].

3.5. Transition Flow Experiment (TRANSFLEX), Phoenix, USA. The TRANSFLEX experiments were conducted between January 7 and 17, 2006, in Phoenix, Arizona, USA, to understand the transition mechanism in the evening [34]. The experiments were supported by the Arizona Department of Environmental Quality due to concerns on poor air quality in the region; very often the $\mathrm{PM}_{10}$ limit of $50 \mu \mathrm{g} / \mathrm{m}^{3}$ (yearly average) was exceeded. For this purpose, two sites, namely, Mountain View High School and another site in Southern Phoenix, were chosen since these areas reported high $\mathrm{PM}_{10}$ concentrations. The two main issues of interest in this study were to

(a) study flow reversal due to change in buoyancy;

(b) assess the formation of a transition front.

For this purpose, concentration sensors and tethered balloons were deployed. A general observation during this study was the arrival of the transition period which varied from one site to another, but generally after sunset, a flow reversal (upslope to downslope) was observed. An MM5 urbanised model [35] was used to obtain a general qualitative agreement with measured data. From this study, the authors concluded that a local Richardson number may be suitable for quantifying such events. This study showed that stable stratification may prevent the dispersion of the particulate matter, and generally a transition front could allow entrainment of dust particles in some regions to increase particle concentrations. Unlike most previous studies that were focused on any one particular phenomenon (upslope/downslope flows), this field study is one of the most important studies carried out in recent

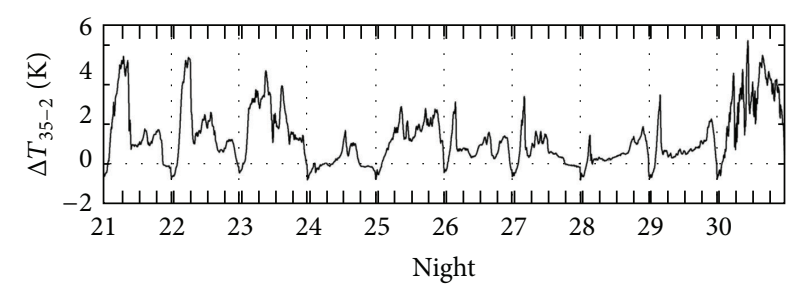

Figure 5: Inversion strength between $35 \mathrm{~m}$ and $2 \mathrm{~m}$ (from [36]).

times, with a particular emphasis on "transitional flows" along mountain slopes and its effect on urban ventilation.

3.6. Stable Atmospheric Boundary Layer Experiment in Spain (SABLES), 2006. The SABLES field study [36] was conducted from June 19 to July 5, 2006, at Valladolid, Spain. Although this location consists of a relatively flat terrain, it is surrounded by two small slopes of 1:6000 and 1:1660, respectively [37]. The instruments employed for this study were similar to some of the previous field measurements, namely, sonic anemometers and wind vanes (wind velocity) and microbarometers to measure the absolute pressure at various heights and tethered balloons for night time wind conditions. Although some of the main objectives of this field study were to assess mean micrometeorological variables, stability, and turbulent parameters, the effects of katabatic flows were mainly observed from some of their results. For instance, Figure 5 shows the inversion strength between $2 \mathrm{~m}$ and $35 \mathrm{~m}$ from June 21 to June 30,2006 . Results show that the temperature changes on certain days (e.g., June 28 and June 29) are markedly different from other days (e.g., June 21 and June 22). According to [36], "Katabatic winds (radiatively cooled air descending along local slopes) are the most probable cause for this behaviour." In fact, shallow slopes are capable of producing drainage flows of about $1-2 \mathrm{~m} / \mathrm{s}$, as reported in Wangara, Australia, and the Great Plains, USA [38].

The significance of buoyancy driven flows, especially nocturnal drainage (katabatic) flows, in diluting pollutant concentrations and cooling regions located at the foot of the mountains can be observed from this study. One of the important features that distinguishes this study from the rest is that the SABLES study consisted of mountains with shallow slopes (earlier studies had steeper slopes) which produced significant slope winds to ventilate a city. However, most previous studies tried to quantify the ventilation rate in terms of wind speeds along slopes and observed reduction in concentration of pollutants (e.g., during katabatic winds), although the field study at the University of Hong Kong (described next) is uniquely different.

3.7. Field Studies at The University of Hong Kong, SAR China. Compared to most other field studies that employed tethered balloons and anemometers to assess mountain slope winds, the field study at The University of Hong Kong (HKU) utilised a thermal infrared camera [14]. Yang and Li carried out field measurements using an infrared camera to assess surface temperatures on building surfaces. They used the concept of 


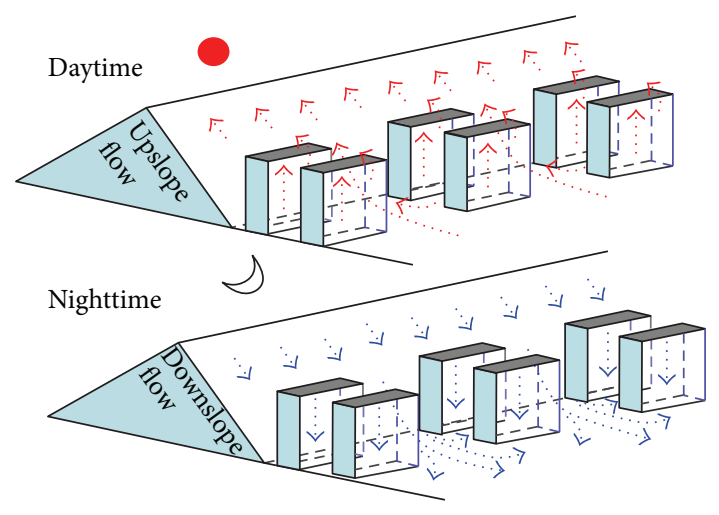

FIGURE 6: Schematic 3D illustration of the slope wind and wall flow system (from [14]).

air changes per hour $(\mathrm{ACH})$ to quantify urban ventilation rates due to buildings and mountain slopes in Hong Kong and also considered the effects of Sky View Factor, which was not a part of previous experimental studies [14]. According to their study (Figure 6), the heating of the building wall surfaces and mountain slopes during the day produced upward buoyancy driven flow, whilst the air from the Victoria harbour replaced this upward air.

At night the opposite happens (Figure 6) and there is a downward flow of air due to the cooling of the building and mountain surfaces. Yang and Li. [14] state that "The slope flows and wall flows dominate the city ventilation when the large scale flows (or mesoscale sea-land breezes) are weak, that is, no-wind conditions." In fact, this study also showed that the $\mathrm{ACH}$ values of wall flows were significantly higher than slope flows. Most previous studies focused only on katabatic/anabatic mountain flows, without considering the contribution of the building surfaces (vertical walls), and, therefore, the findings of this study are very important in the context of city ventilation.

3.8. Field Measurements of Buoyancy Flow on a Building Wall in Japan. A comprehensive outdoor scale model (COSMO) facility to study the natural convection flows along building walls in a street canyon was carried out at the Nippon Institute of Technology, Japan, in December 2008 (Figure 7), by Onomura et al. [16]. The windward and leeward wall sections were heated alternately and particle image velocimetry (PIV) was used to visualise the flow patterns at night. According to Onomura et al. [16], "Shear stress is strong at the top of the street canyon in the heating cases. In the windward wall heating case, a heated wall enhances turbulence within the canyon. Reynolds stress is distinguished at the top of the canyon in the leeward wall heating case."

An extension of this study was carried out by Nottrott et al. [6] (see Figure 8) using sonic anemometers and thermocouples.

This study was conducted in July 2010 at the COSMO test facility to assess thermally induced buoyancy flows within a street canyon. Many studies in the past have investigated the natural convection flows along vertical plates [39], including

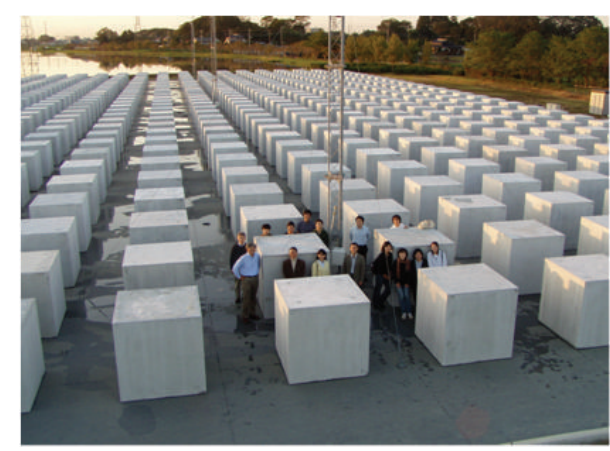

Figure 7: COSMO facility, Japan (from [16]).

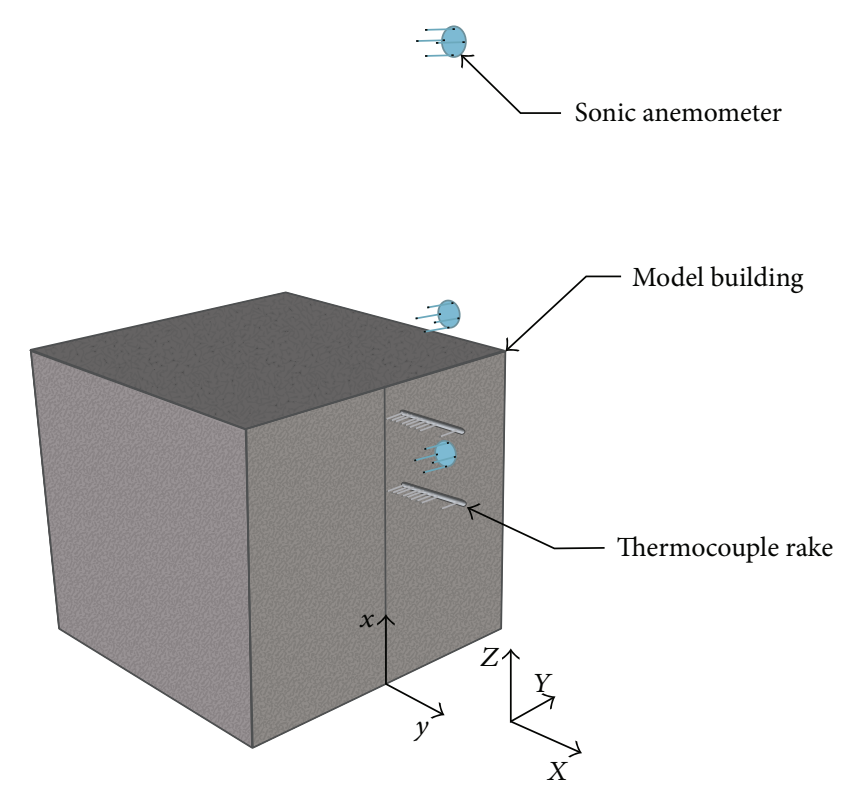

FIgURE 8: A schematic drawing of the experimental setup at COSMO (from [6]).

water channel measurements by Tsuji and Nagano [40]. However, no full scale measurements on buildings were conducted, although CFD simulations in street canyons have been carried out by Xie et al. [13] as described later. The sonic anemometers and thermocouples were used to obtain 30-minute continuous datasets for 3 days. They found that turbulent natural convection occurred even in low values of Grashof and Reynolds numbers. Based on different values of building height $(\mathrm{H})$ and distance between buildings $(\mathrm{S})$, Onomura et al. [16] concluded that "decreasing the ratio $H / S$ in cities located in warm climates has the potential to increase convection on leeward building walls, thus reducing overall building cooling load." Table 1 summarises the various physical modelling studies covered in this section, besides additional studies. It is important to realise that in an urban setting surrounded by mountains, buoyancy flows occur due to both buildings and mountains. Therefore, it is necessary for any theory/model to integrate both aspects, which has generally not been the case as discussed further. 


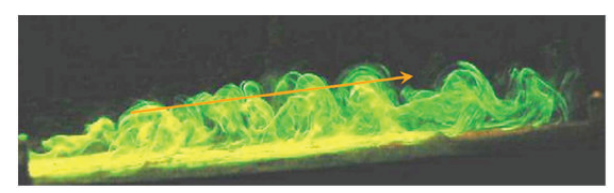

FIGURE 9: Experimental visualization of convection above the sloped heated plate (from [43]).

\section{Theoretical Models Developed/Suggested Based on Field/Laboratory Studies}

Based on field measurements, many theoretical models were developed. Some of the models were used to assess the flow characteristics of buoyancy flows, whilst some of them tried to establish relationships between various parameters. For instance, Monti et al. [41] utilised the data from the VTMX (described earlier in Section 3.2) and found that mean gradient Richardson number and mixing efficiency (flux Richardson number) were closely related. Similarly, Haiden and Whiteman [42] utilised the data from the VTMX experiments and found that the acceleration of katabatic flows at two different sites was different from those predicted from observed buoyancy. This departure in results was attributed to the unevenness of the slopes, which otherwise appeared smooth to any observer. Based on these observations, Haiden and Whiteman suggested that the momentum and heat budget equations must be revisited.

Upslope buoyancy driven flows were studied by Princevac and Fernando [43] using water channel measurements on a heated inclined slope (Figure 9).

They found that the heated thermals had a tendency to travel upwards along an inclined slope at a particular Prandtl number $(\operatorname{Pr})$ and slope angle $(\beta)$ and established a relationship for upslope flow to sustain at $\beta=c(\operatorname{Pr})$. Based on the laboratory measurements, Princevac and Fernando concluded that for small slope angles (about $0.1^{\circ}$ ), the upslope flows were possible and this was found to be consistent with findings from the field study at Phoenix, USA (see Section 3.5), and SABLES study (Section 3.6), where even slopes of about $0.18^{\circ}$ also produced anabatic flows.

Similarly, Princevac and his coresearchers utilised the results from VTMX study (Section 3.2) and developed a relationship for the downslope wind velocity, slope length and angle, and buoyancy jump between current and background atmosphere, for different stability conditions [44]. They showed that the katabatic flows exhibited pulsations with a time period proportional to the buoyancy frequency of the background atmosphere. Their theory which was supported by the VTMX study suggested that the internal wave oscillations were partly responsible for weak sustained turbulence, often observed in nocturnal flows.

There are other studies on analytical models that have tried to model mountain slope flows [45]. For instance, Zammett and Fowler [46] modified the classical Prandtl model to simulate katabatic flows on mountain slopes with glaciers and ice sheets. Their study showed that the improved model compared well with observations and other available

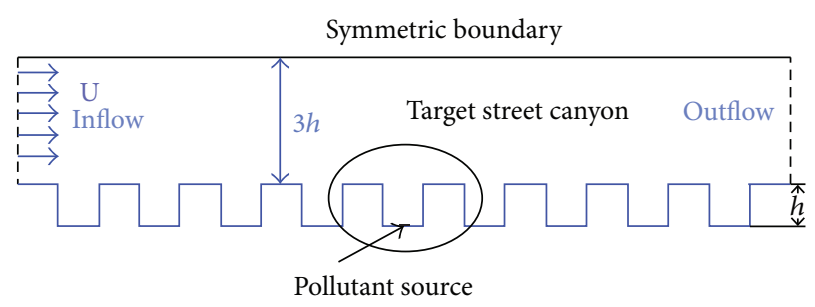

FIGURE 10: Schematic diagram of the computational domain and boundary conditions (from [13]).

regional models. A model to simulate nocturnal low level jets over slopes, such as the Great plains in USA, was developed by Shapiro and Fedorovich in 2009 [47], "to include upand downslope motion in the boundary layer within a stably stratified environment."

\section{CFD Simulations of Buoyancy Driven Flows in Nature}

Most CFD simulations have utilised $\mathrm{k}-\varepsilon$ based model. For instance, Xie et al. [48] used the renormalisation group (RNG) $\mathrm{k}-\varepsilon$ model to assess the effect of solar radiation on building walls and the resulting buoyancy flows in a street canyon. Their simulations showed that the air exchange rate increased with heating intensity, but decreased with increasing Reynolds number. Furthermore, they also developed a regression based model relating the air exchange rate and heating intensity.

The authors extended their study on street canyons (Figure 10) by varying the street canyon aspect ratio (building height $\mathrm{H}$ to street width $\mathrm{W}$ ) using the RNG $\mathrm{k}-\varepsilon$ model as described in [13]. They found that "In contrast to single surface heating, the multi-surface-heating configuration has greater influence on the flow field and pollutant transport in the street canyons."

For instance, Figure 11 shows normalised pollutant concentration profiles for two different cases.

Additionally, they also found that the street canyon aspect ratio was a dominant factor in altering the flow characteristics. A similar CFD study on the flow and dispersion of pollutants within a street canyon was also carried out by Wang et al. [49] and they found that "When the windward wall is warmer than the air, an upward buoyancy flux opposes the downward advection flux along the wall, and divides the flow structure into two counter-rotating vortices indicating a clockwise top vortex and a reverse lower vortex within the canyon." Due to advancements in computer speeds, Large Eddy Simulations (LES) of mountain slope flows have also been carried out recently. For instance, Skyllingstad [50] carried out LES simulations of a steep $\left(20^{\circ}\right)$ and a gentle slope $\left(1^{\circ}\right)$ and stated that "Comparison of the gentle slope case with a flat terrain simulation indicates that drainage winds can effectively prevent the formation of very stable boundary layers, at least near the top of sloping terrain." Other examples include Axelsen and Van Dop [51, 52] who also performed LES simulations of katabatic winds and found reasonable 


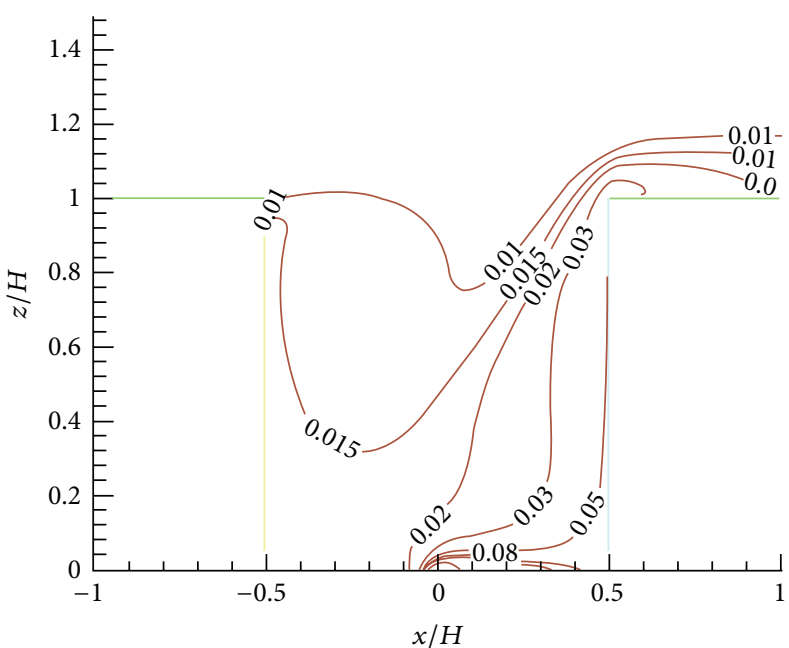

(a)

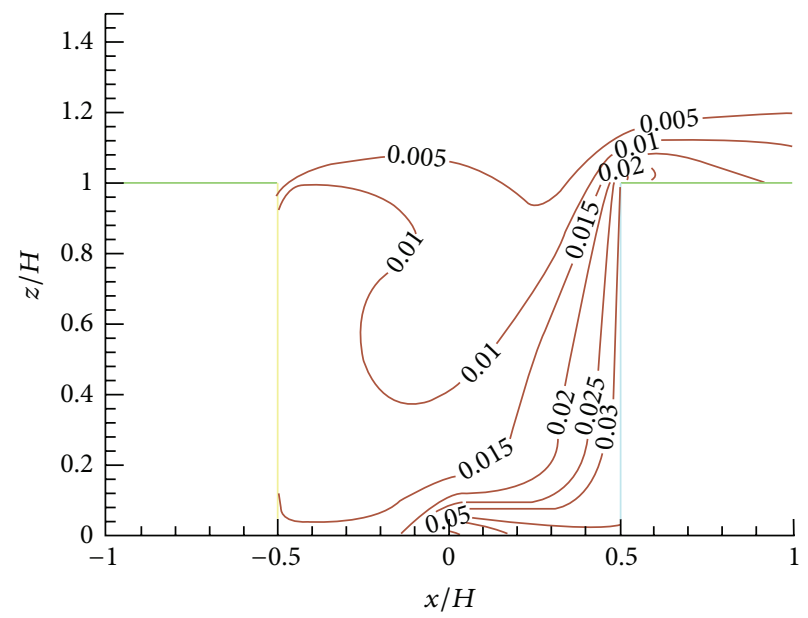

(b)

FIGURE 11: Spatial contours of normalised pollutant concentration $C / C_{0}$ in street canyon with different surfaces heated in aspect ratio 1: (a) ground heated; (b) leeward façade and ground heated (from [13]).

agreement with some previous simulations from Schumann [53].

A more recent CFD study using the $\mathrm{k}-\varepsilon$ model that includes the buoyancy effects of buildings and mountain slopes on city ventilation was carried out by Luo and $\mathrm{Li}$ [15] (Figure 12). The ventilation of the city of Hong Kong was evaluated in terms of air changes per hour and age of air concepts. From their studies they stated that "When the building is lower than $60 \mathrm{~m}$, the slope wind dominates. When the building is as high as $100 \mathrm{~m}$, the contribution from the urban wall flow cannot be ignored."

Luo and $\mathrm{Li}$ [15] found from their simulations that slope flows (particularly katabatic flows) are highly beneficial in ventilating a city. However, due to increased urbanisation in Hong Kong (high rise buildings), building walls significantly increased the buoyancy driven flows as opposed to mountains. Compared to most previous studies which mainly focused on any one aspect (mountain slope or building wall in street canyon), this study dealt with the effects of both building walls and mountain slopes which is more realistic.

\section{Discussion}

This review mainly covered some recent studies (after 2000) on buoyancy driven flows in nature (mountain slopes and buildings) and its influence on reducing pollution levels in a city. Some issues that are worthy of discussion from this review are as follows.

6.1. Instrumentation and Quantification of Buoyancy Flows. Most studies discussed in this paper (e.g., VTMX and TRANSFLEX studies) have mainly utilised tethered balloons, LIDARS, SODARS, and sonic anemometers to assess mountain slope flows, whilst the field study at the University of Hong Kong (Section 3.7) utilised an infrared camera. This is a significant improvement in technology, because infrared cameras were originally designed for military use [54], but these have been used only recently for estimating surface temperatures (e.g., [14]). This makes measurements much more convenient since these thermal cameras can be installed almost anywhere to measure the temperature of a particular surface (ground, building, or mountain slope), besides being cost effective (e.g., tethered balloons are quite expensive). Furthermore, using a tethered balloon has certain disadvantages for meteorological measurements and as aptly described by Parker et al. [55] "the familiar pressurized balloons made of latex are easily ruptured by sharp objects in canopies, or because the sizes of the canopy spaces that accommodate balloons might limit the payload." Additionally, strong winds may affect the measurements made by tethered balloons. In recent times, unmanned aerial vehicles [56] have been used for meteorological measurements over volcanic mountains (e.g., [57]) and may be an alternative for tethered balloons in future. Obviously, these problems are overcome by using an infrared camera. More recently, Onomura et al. [16] have even used an infrared camera to measure 2D wind velocity distribution on a building surface exposed to solar radiation. They used the thermal image velocimetry (TIV) concept of tracking brightness temperature images to measure the wind velocities and reported excellent comparisons with measurements from sonic anemometers. Indeed, gradually new technology to facilitate the measurement of buoyancy driven flows is being developed and is very important in the context of city ventilation.

Some studies on UHI have also estimated the air temperatures in rural and urban areas of Hong Kong using satellite images (e.g., [58]), although the data from those studies have actually never been used to study buoyancy driven flows (slope and wall flows and improving wind conditions in the city), but one should expect satellite imaging to be a promising tool of the future for city ventilation studies. 


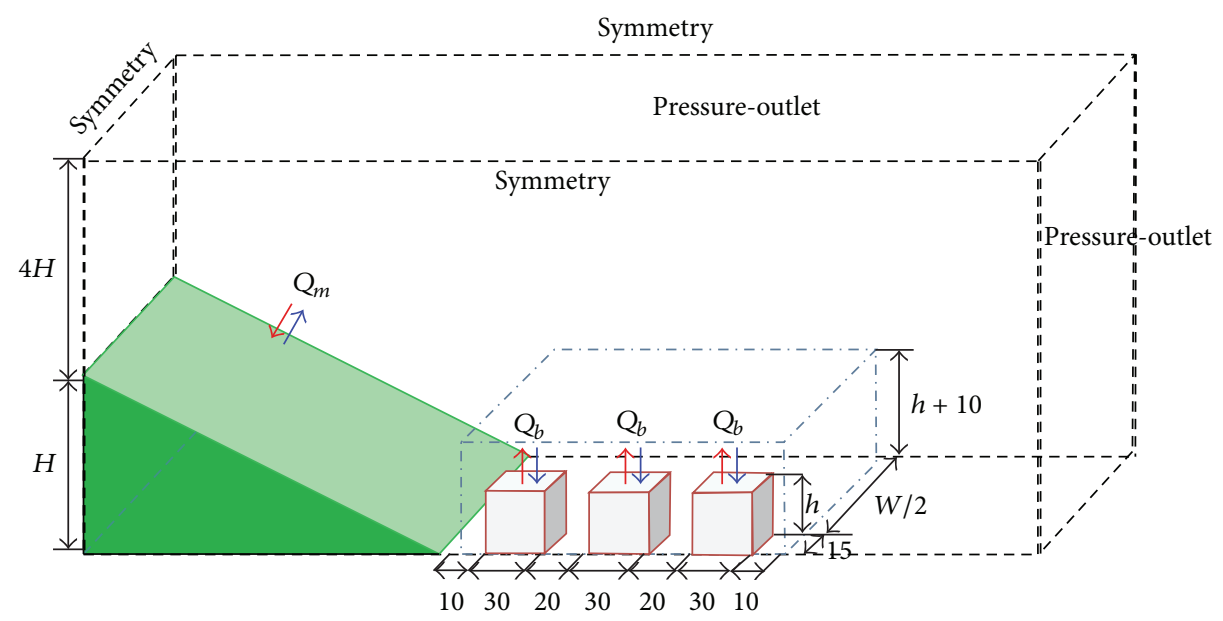

FIGURE 12: Computational model of mountain slope and building blocks (from [15]).

Furthermore, most studies have tried to quantify the effect of buoyancy induced flows in nature using wind speeds (along slopes) or tracer concentrations in valleys (e.g., VTMX and ASCOT studies). However, more recent studies by [14] and [15] have utilised the air changes per hour concept that was originally used in building ventilation [59] and extended it to urban ventilation flows. Of particular importance is the successful application of empirical relations (e.g., the velocity and thickness of the thermal boundary layer on a wall by [19] utilised by Yang and Li [14] for urban flows), which is a significant improvement with regards to the quantification of urban ventilation.

In general, the field measurements of buoyancy driven flows should adopt a systematic approach depending on the parameter being measured and the location of measurement.

(a) Locations that are difficult to access: while measuring surface temperatures on a mountain slope or high rise building, it may be difficult to fix thermocouples on these surfaces. Therefore, in such cases, an infrared camera could be most useful since this can provide greater ease of measurement with high accuracy [14]. In order to measure buoyancy driven wind velocities, sonic anemometers as well as infrared images to assess $2 \mathrm{D}$ wind speeds may be utilised.

(b) Larger areas of measurement: while covering larger areas (such as New York), satellite imaging technology to gather urban surface temperature data (e.g., [58]) can be useful, since infrared cameras cannot cover such larger areas of interest. On certain locations on the urban surface, thermocouples can be used in order to compare with satellite data.

(c) Measuring parameter: if the parameter being measured is wind velocity, sonic anemometers are extremely accurate and convenient due to their light weight (compared to the conventional weather stations) making it easier to install them at any location. A weather station should be used only if additional parameters (e.g., humidity, air temperature etc.) are being measured, although in such cases only limited measurements at certain critical locations may be carried out.

6.2. Flow Processes in the Urban Environment. It is understandable that the buoyancy driven flows in the urban environment are too intricate and are not fully understood yet. One of the key issues is modelling the flow appropriately. For a populated city surrounded by skyscrapers and mountains (e.g., Hong Kong), it is not realistic to simulate any one process in particular. For instance, most previous studies (e.g., VTMX and ASCOT field measurements) have mostly focused on mountain slope flows, whilst some of them have tried to simulate buoyancy flows only due to building walls in a street canyon (e.g., [48]). But in reality, an urban area consists of many sources of buoyancy driven flows, which include buildings, mountains and other structures (e.g., transmission line towers, cooling towers and industrial chimneys, and trees that are sufficiently tall) and humans. Most studies particularly, numerical simulations, generally consider only one aspect (only mountain slopes or only building walls), the only exception being the study by Luo and $\mathrm{Li}$ [15] which considered both aspects. For instance, Gao and Niu found that the Rayleigh number (product of Grashof and Prandtl numbers) at the head level of a human being is approximately $4.1 \times 10^{9}$, indicating a turbulent nature of flow [60]. In a highly populated city like Hong Kong with a population of above 7 million, each person living in the city can greatly contribute to the buoyancy driven flow. Furthermore, additional structures (e.g., industrial stacks and tall trees) could also contribute to natural convection flows, and therefore future studies must take account of this for realistic cases.

It is worth noting that most studies have tried to estimate the dispersion of tracers (e.g., in TRANSFLEX study) due to katabatic/downslope winds, with very few studies on anabatic/upslope winds (e.g., Section 3.3). Buoyancy driven flows become particularly important for city ventilation when the synoptic winds are weak and interestingly most studies 
(particularly, field measurements) have not highlighted the difficulty encountered in measuring city ventilation rates for each case (presence of synoptic winds and absence of synoptic winds). In fact, the study by Reuten et al. [30] is the only study that has highlighted this problem. For instance, in one of their measurements in the convective boundary layer $(\mathrm{CBL})$, they found that during the day the upslope flow along a mountain had a tendency to develop a "clockwise rotation" after a certain distance up the slope. Reuten et al. [30] stated that "We cannot give a conclusive explanation for the observed wind directions but suspect a superposition of the synoptic wind with an upslope flow in the bottom part of the CBL and with a return flow in the upper part of the CBL." However, this difficulty can be countered using CFD simulations, since each effect (buoyancy and synoptic winds; buoyancy without synoptic winds) can be studied separately or as a combination.

6.3. Computational and Analytical Models. Since, field measurements may not always be possible due to financial and time constraints, computer based simulations of buoyancy driven flows will dominate the future and the results obtained from previous field measurements will be useful for validation. The main problem with any model is that none of them can actually represent the physics of the entire process accurately. For instance, conventional mesoscale models like MM5 [35] use the "roughness approach" to replicate urban elements (buildings) and although MM5 was found to be useful in the TRANSFLEX study of mountain slope flows (Section 3.5) its application for an urban site consisting of building and mountains may be less accurate. Similarly, other empirical/analytical models (e.g., [61]) that were developed from laboratory measurements may not be applicable for modelling urban flows.

It may be necessary to analyse the problem in a slightly different manner. For instance, the concept of $\mathrm{ACH}$ which was initially used for building ventilation was later used for city ventilation studies [14]. It is worth noting that a study carried out by $\mathrm{Xi}$ et al. [62] has reported many "plumevortex" and "plume-plume" interactions, based on RayleighBenard turbulent convection experiments carried out in a convection cell, with the bottom and top plates being heated and cooled, respectively. This experimental set up is very much representative of a large city which is heated at the bottom (ground surface) and cooled at the top (top of the urban canopy layer). Although their study was for Rayleigh numbers of about $10^{8}$, whilst the natural convection flows in nature are of much higher Rayleigh numbers, the results from [62] may be applied to the study of city ventilation, although this is just a speculation and the effectiveness of the application of this concept can only be verified by future researchers.

From the various studies reviewed, it is clear that even today most people use the $\mathrm{k}-\varepsilon$ based models to simulate buoyancy flows [15]. However, Direct Numerical simulation and LES may be better alternatives given the recent improvements in high speed computers, and, in fact, some LES studies on mountain slope flows have yielded excellent results [50]. It is understandable that CFD using LES may be a widely used tool

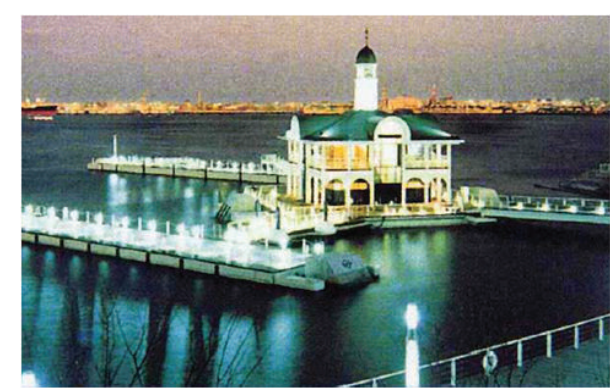

FIGURE 13: Floating restaurant in Yokohama, Japan (from [63]).

in future, but experiments and numerical modelling must be done in parallel to improve the latter.

\subsection{Designing a City for Better Wind Conditions and Reduced} Pollution Levels. For a developed city like Hong Kong consisting of a large built up area (which reduces wind penetration) and numerous structures (mountains and buildings contributing to the buoyancy flows), besides high population and acute shortage of land, very few options to improve the city ventilation conditions exist. One option may be to use very large floating structures (VLFS), as described in [63]. These structures have been employed (Figure 13) in the past, particularly in coastal regions where there is shortage of land.

This can avoid the further construction of skyscrapers which have otherwise lead to reduced wind speeds in cities like Hong Kong [64, 65].

Another widely used method discussed by many researchers is the planting of trees that can reduce UHI effects, improve day-lighting and wind conditions in a city [66]. Similar concepts were earlier used to develop "green roofs" [67], and now the same is being extended to the city scale. Another example is the numerical simulations carried out by Hong et al. [68] for a district in Beijing to assess thermal and wind conditions due to trees for various "parameters" (tree locations, distance between trees and buildings, type of tree, etc.).

\section{Future Developments}

As human civilization expands, particularly in cities located amidst mountains (e.g., Hong Kong and Phoenix), air pollution (particulate matter from industries and vehicles; anthropogenic heat, etc.) will also rise. Obviously, the developments that arise in future will stem from the deficiencies encountered currently. Some of the key issues faced by researchers today are as follows.

(a) Understanding of the problem: Fernando [3] has rightly stated that "Fluid mechanics is inextricably related to fundamental developments in urban meteorology," and therefore it is important to realise that any model (theoretical/empirical) must capture the complete mechanism in the urban scenario. For instance, previous studies exclusively focusing on any one aspect (wall or slope flow) are not fully accurate. 
(b) Modelling issues and coordination between experimentalists and physicists: once the problem is fully understood, modelling it using CFD, particularly using LES, is preferred. Although $\mathrm{k}-\varepsilon$ models do not require high speed computers, as opposed to LES, the latter is much more accurate for modelling these flows. More importantly, CFD results must be validated either from previous field measurements or from laboratory simulations and this will require collaborations between physical modellers and computational scientists. This collaboration is essential, since computational modelling is expected to make an impact in future, considering the time and financial factors involved in field studies, although it is expected that laboratory simulations (e.g., water channel measurements) will certainly continue in future and will possibly be a major source of experimental data for CFD scientists. However, accurate modelling of these flows in water channels is essential. For instance, Reuten et al. [10] considered three different "Pi" groups for simulation of slope flows in a water tank and found that despite equality of the "Pi" groups, "similarity of maximum upslope flow velocity in atmosphere and water tank was violated by a factor of more than two." Reuten et al. [10] further stated that "We speculate that differences in Reynolds number and roughness height between tank and atmosphere may be the cause for the velocity similarity violation." Therefore, it is important to have an accurate simulation of urban buoyancy flows in laboratory measurements and this may require revisiting of some of the existing similarity criteria being currently followed.

(c) Better instrumentation for field measurements: it has often been observed that most studies have tried to estimate the wind velocities using various measurement techniques along slopes with very little effort to estimate whether these "velocities" were caused by a combination of buoyancy flow and synoptic winds or due to any one individual "component." Therefore, future instrumentation should be capable of distinguishing each "component" of flow. With so much wireless technology rising, it may be possible to have this technology applied to the procurement of data, especially in remote locations which may be difficult to access [69]. Similarly, unmanned vehicles [70] with global positioning system may be used for meteorological observations.

(d) Designing a city for improved wind and thermal conditions: it is important for designers to come up with design codes/guidelines that can help upcoming cities that are located amidst mountains where buoyancy driven flows could play a major role in city ventilation. Some of these criteria should include building dimensions (max. allowable height/width to enable wind penetration), width of streets, allowable emissions (from vehicles, industries, etc.), and location of these industries within the city. Other options such as cool roofs and tree plantation, besides using specific building construction materials (e.g., $[71,72]$ ) to provide a cooler environment, should also be investigated in detail.

\section{Conclusions}

The following may be concluded based on the review of recent work (after 2000) on buoyancy driven flows in nature. (a) Most field studies were focused on mountain slope flows, with limited research on buoyancy driven flows along a building wall. Additional "urban buoyancy flow" studies focusing on the combined effect of "building wall" and "mountain slope" are necessary.

(b) Field measurement techniques to assess buoyancy driven flows in the urban environment have gradually improved from tethered balloons to the use of infrared camera for estimating surface temperatures [14] and wind velocities [73].

(c) CFD simulations have mostly focused on $\mathrm{k}-\varepsilon$ based models of wall flows [13], with limited studies applying LES modelling of slope flows [50], and few studies focused on the combined effect of building wall and slope flows [15].

(d) Analytical and empirical relations based on laboratory measurements have not been successfully applied for geophysical scales, and, hence, a proper understanding of the physical processes associated with buoyancy driven flows in nature is necessary.

(e) In future, collaboration between physical modellers and computational scientists to improve CFD modelling is necessary. Furthermore, design guidelines to generate improved wind conditions in a city, taking account of buoyancy flows to mitigate urban air pollution, must be developed.

\section{Conflict of Interests}

The author declares that there is no conflict of interests regarding the publication of this paper.

\section{References}

[1] M. Oppenheimer, "Global warming and the stability of the West Antarctic ice sheet," Nature, vol. 393, no. 6683, pp. 325-332, 1998.

[2] D. L. Davis, M. L. Bell, and T. Fletcher, "A look back at the London smog of 1952 and the half century since," Environmental Health Perspectives, vol. 110, no. 12, pp. A734-A735, 2002.

[3] H. J. S. Fernando, "Fluid dynamics of urban atmospheres in complex terrain," Annual Review of Fluid Mechanics, vol. 42, pp. 365-389, 2010.

[4] J. Hang, M. Sandberg, and Y. Li, "Effect of urban morphology on wind condition in idealized city models," Atmospheric Environment, vol. 43, no. 4, pp. 869-878, 2009.

[5] J. C. R. Hunt, H. J. S. Fernando, and M. Princevac, "Unsteady thermally driven flows on gentle slopes," Journal of the Atmospheric Sciences, vol. 60, pp. 2169-2182, 2003.

[6] A. Nottrott, S. Onomura, A. Inagaki, M. Kanda, and J. Kleissl, "Convective heat transfer on leeward building walls in an urban environment: measurements in an outdoor scale model," International Journal of Heat and Mass Transfer, vol. 54, no. 1516, pp. 3128-3138, 2011.

[7] R. Giridharan, S. Ganesan, and S. S. Y. Lau, "Daytime urban heat island effect in high-rise and high-density residential developments in Hong Kong," Energy and Buildings, vol. 36, no. 6, pp. 525-534, 2004. 
[8] S. Di Sabatino, B. C. Hedquist, W. Carter, L. S. Leo, and H. J. S. Fernando, "The phoenix, urban heat island experiment: effects of built elements," in American Meteorological Society, 89th Annual Meeting, pp. 10-16, Phoenix, Ariz, USA, January 2009.

[9] H. J. S. Fernando, D. Zajic, S. Di Sabatino, R. Dimitrova, B. Hedquist, and A. Dallman, "Flow, turbulence, and pollutant dispersion in urban atmospheres," Physics of Fluids, vol. 22, no. 5, pp. 1-20, 2010.

[10] C. Reuten, D. G. Steyn, and S. E. Allen, "Upslope flows in atmosphere and water tank, part I: scaling," The Open Atmospheric Science Journal, vol. 4, pp. 178-187, 2010.

[11] W. E. Clements, J. A. Archuleta, and P. H. Gudiksen, "Experimental design of the 1984 ASCOT field study," Journal of Applied Meteorology, vol. 28, no. 6, pp. 405-413, 1989.

[12] P. H. Gudiksen and D. L. Shearer, "The dispersion of atmospheric tracers in nocturnal drainage flows," Journal of Applied Meteorology, vol. 28, no. 7, pp. 602-608, 1989.

[13] X. Xie, C.-H. Liu, and D. Y. C. Leung, "Impact of building facades and ground heating on wind flow and pollutant transport in street canyons," Atmospheric Environment, vol. 41, no. 39, pp. 9030-9049, 2007.

[14] L. Yang and Y. Li, "City ventilation of Hong Kong at no-wind conditions," Atmospheric Environment, vol. 43, no. 19, pp. 31113121, 2009.

[15] Z. Luo and Y. Li, "Passive urban ventilation by combined buoyancy-driven slope flow and wall flow: parametric CFD studies on idealized city models," Atmospheric Environment, vol. 45, no. 32, pp. 5946-5956, 2011.

[16] S. Onomura, S. Takimoto, and M. Kanda, "Influence of a heated wall on urban canopy flow using PIV measurements," in Proceedings of the 7th International Conference on Urban Climate, Yokohama, Japan, June-July 2009.

[17] Y. Jaluria, Natural Convection Heat and Mass Transfer, Pergamon Press, Oxford, UK, 1980.

[18] P. Chandran, N. C. Sacheti, and A. K. Singh, "Natural convection near a vertical plate with ramped wall temperature," Heat and Mass Transfer, vol. 41, no. 5, pp. 459-464, 2005.

[19] E. R. G. Eckert and T. W. Jackson, "Analysis of Turbulent FreeConvection Boundary Layer on Flat Plate," NACA Report 1015, 1951.

[20] C. D. Whiteman, Mountain Meteorology: Fundamentals and Applications, Oxford University Press, New York, NY, USA, 2000.

[21] D. Zardi and C. D. Whiteman, "Diurnal mountain wind systems," in Mountain Weather Research and Forecasting: Recent Progress and Current Challenges, pp. 35-119, Springer, New York, NY, USA, 2012.

[22] F. Defant, "Local winds," in Compendium of Meteorology, pp. 655-672, American Meteorological Society, Boston, Mass, USA, 1951.

[23] C. D. Whiteman, "Observations of thermally developed wind systems in mountainous terrain," AMS Meteorological Monographs, vol. 45, pp. 5-42, 1990.

[24] S. Ostrach, "An analysis of laminar free convection flow and heat transfer about a flat plate parallel to the direction of the generating body force," NACA Technical Report 1111, 1953.

[25] J. S. Turner, Buoyancy Effects in Fluids, Cambridge University Press, Cambridge, UK, 1973.

[26] B. Gebhart, Y. Jaluria, R. L. Mahajan, and B. Sammakia, Buoyancy Induced Flows and Transport, Hemisphere Publishing, New York, NY, USA, 1988.
[27] A.-J. N. Khalifa, "Natural convective heat transfer coefficienta review I. Isolated vertical and horizontal surfaces," Energy Conversion and Management, vol. 42, no. 4, pp. 491-504, 2001.

[28] M. M. Orgill, "Early morning ventilation of a gaseous tracer from a mountain valley," Journal of Applied Meteorology, vol. 28, no. 7, pp. 636-651, 1989.

[29] J. C. Doran, J. D. Fast, and J. Horel, “The VTMX 2000 campaign," Bulletin of the American Meteorological Society, vol. 83, no. 4, pp. 537-551, 2002.

[30] C. Reuten, D. G. Steyn, K. B. Strawbridge, and P. Bovis, "Observations of the relation between upslope flows and the convective boundary layer in steep terrain," Boundary-Layer Meteorology, vol. 116, no. 1, pp. 37-61, 2005.

[31] H. Huang, R. Ooka, and S. Kato, "Urban thermal environment measurements and numerical simulation for an actual complex urban area covering a large district heating and cooling system in summer," Atmospheric Environment, vol. 39, no. 34, pp. 63626375, 2005.

[32] R. Ooka, H. Chen, and S. Kato, "Study on optimum arrangement of trees for design of pleasant outdoor environment using multi-objective genetic algorithm and coupled simulation of convection, radiation and conduction," Journal of Wind Engineering \& Industrial Aerodynamics, vol. 96, no. 10-11, pp. 1733-1748, 2008.

[33] A. Mochida and I. Y. F. Lun, "Prediction of wind environment and thermal comfort at pedestrian level in urban area," Journal of Wind Engineering and Industrial Aerodynamics, vol. 96, no. 10-11, pp. 1498-1527, 2008.

[34] H. J. S. Fernando, B. Verhoef, S. di Sabatino, L. S. Leo, and S. Park, "The phoenix evening transition flow experiment (TRANSFLEX)," Boundary-Layer Meteorology, vol. 147, no. 3, pp. 443-468, 2013.

[35] S. Dupont, T. L. Otte, and J. K. S. Ching, "Simulation of meteorological fields within and above urban and rural canopies with a mesoscale model," Boundary-Layer Meteorology, vol. 113, no. 1, pp. 111-158, 2004.

[36] C. Yague, S. Viana, G. Maqueda, M. F. Lazcano, G. Morales, and J. M. Rees, "A study on the nocturnal atmospheric boundary layer: SABLES2006," Física de la Tierra, vol. 19, pp. 37-53, 2007.

[37] J. Cuxart, C. Yague, G. Morales et al., "Stable atmospheric boundary-layer experiment in Spain (sables 98): a report," Boundary-Layer Meteorology, vol. 96, no. 3, pp. 337-370, 2000.

[38] R. B. Stull, An Introduction to Boundary Layer Meteorology, Kluwer Academic Publishers, Dordrecht, The Netherlands, 1988.

[39] R. Cheesewright, "Turbulent natural convection from a vertical plane surface," Journal of Heat Transfer, vol. 90, pp. 1-8, 1968.

[40] T. Tsuji and Y. Nagano, "Characteristics of a turbulent natural convection boundary layer along a vertical flat plate," International Journal of Heat and Mass Transfer, vol. 31, no. 8, pp. 17231734, 1988.

[41] P. Monti, H. J. S. Fernando, M. Princevac, W. C. Chan, T. A. Kowalewski, and E. R. Pardyjak, "Observations of flow and turbulence in the nocturnal boundary layer over a slope," Journal of the Atmospheric Sciences, vol. 59, no. 17, pp. 2513-2534, 2002.

[42] T. Haiden and C. D. Whiteman, "Katabatic flow mechanisms on a low-angle slope," Journal of Applied Meteorology, vol. 44, no. 1, pp. 113-126, 2005.

[43] M. Princevac and H. J. S. Fernando, "A criterion for the generation of turbulent anabatic flows," Physics of Fluids, vol. 19, no. 10, Article ID 105102, 2007. 
[44] M. Princevac, J. C. R. Hunt, and H. J. S. Fernando, "Quasi-steady katabatic winds on slopes in wide valleys: hydraulic theory and observations," Journal of the Atmospheric Sciences, vol. 65, no. 2, pp. 627-643, 2008.

[45] R. G. Barry, Mountain Weather and Climate, Cambridge University Press, Cambridge, UK, 3rd edition, 2008.

[46] R. J. Zammett and A. C. Fowler, "Katabatic winds on ice sheets: a refinement of the Prandtl model," Journal of the Atmospheric Sciences, vol. 64, no. 7, pp. 2707-2716, 2007.

[47] A. Shapiro and E. Fedorovich, "Nocturnal low-level jet over a shallow slope," Acta Geophysica, vol. 57, no. 4, pp. 950-980, 2009.

[48] X. Xie, C. H. Liu, D. Y. C. Leung, and M. K. H. Leung, "Characteristics of air exchange in a street canyon with ground heating," Atmospheric Environment, vol. 40, no. 33, pp. 63966409, 2006.

[49] P. Wang, D. Zhao, W. Wang, H. Mu, G. Cai, and C. Liao, "Thermal effect on pollutant dispersion in an urban street Canyon," International Journal of Environmental Research, vol. 5, no. 3, pp. 813-820, 2011.

[50] E. D. Skyllingstad, "Large-eddy simulation of katabatic flows," Boundary-Layer Meteorology, vol. 106, no. 2, pp. 217-243, 2003.

[51] S. L. Axelsen and H. Van Dop, "Large-eddy simulation and observations of slope flow," Acta Geophysica, vol. 57, pp. 803836, 2008.

[52] S. L. Axelsen and H. van Dop, "Large-eddy simulation of katabatic flow over an infinite slope," Acta Geophysica, vol. 57, no. 4, pp. 837-856, 2009.

[53] U. Schumann, "Large-eddy simulation of the up-slope boundary layer," Quarterly Journal of the Royal Meteorological Society, vol. 116, no. 493, pp. 637-670, 1990.

[54] N. C. Currie, F. J. Demma, D. D. Ferris Jr., B. R. Kwasowsky, R. W. McMillan, and M. C. Wicks, "Infrared and millimeter-wave sensors for military special operations and law enforcement applications," International Journal of Infrared and Millimeter Waves, vol. 17, no. 7, pp. 1117-1138, 1996.

[55] G. G. Parker, P. J. Stone, and D. Bowers, "A balloon for microclimate observations within the forest canopy," Journal of Applied Ecology, vol. 33, no. 1, pp. 173-177, 1996.

[56] K. Nonami, F. Kendoul, S. Suzuki, W. Wang, and D. Nakazawa, Autonomous Flying Robots: Unmanned Aerial Vehicles and Micro Aerial Vehicles, Springer, 1st edition, 2010.

[57] D. Pieri, J. A. Diaz, G. Bland et al., "In situ observations and sampling of volcanic emissions with NASA and UCR unmanned aircraft, including a case study at turrialba volcano, Costa rica," Geological Society Special Publication, vol. 380, no. 1, pp. 321-352, 2013.

[58] J. E. Nichol, W. Y. Fung, K.-S. Lam, and M. S. Wong, "Urban heat island diagnosis using ASTER satellite images and "in situ" air temperature," Atmospheric Research, vol. 94, no. 2, pp. 276-284, 2009.

[59] D. Etheridge and M. Sandberg, Building Ventilation-Theory and Measurement, John Wiley \& Sons, Chichester, UK, 1996.

[60] N. Gao and J. Niu, "Modeling the performance of personalized ventilation under different conditions of room air and personalized air," HVAC \& R Research, vol. 11, no. 4, pp. 587-602, 2005.

[61] A. J. Wells and M. G. Worster, "A geophysical-scale model of vertical natural convection boundary layers," Journal of Fluid Mechanics, vol. 609, pp. 111-137, 2008.

[62] H. D. Xi, S. Lam, and K. Q. Xia, "From laminar plumes to organized flows: the onset of large-scale circulation in turbulent thermal convection," Journal of Fluid Mechanics, no. 503, pp. 4756, 2004.

[63] E. Watanabe, C. M. Wang, T. Utsunomiya, and T. Moan, "Very large floating structures: applications, analysis and design," Tech. Rep. 2004-02, Centre for Offshore Research \& Engineering (CORE), National University of Singapore, 2004.

[64] W.-L. Ginn, C. Lee, and K.-Y. Chan, "Past and future changes in the climate of Hong Kong," Acta Meteorologica Sinica, vol. 24, no. 2, pp. 163-175, 2010.

[65] E. Ng, Designing High-Density Cities for Social and Environmental Sustainability, Earthscan, Sterling, Va, USA, 2009.

[66] W. Hongbing, Q. Jun, H. Yonghong, and D. Li, "Optimal tree design for daylighting in residential buildings," Building and Environment, vol. 45, no. 12, pp. 2594-2606, 2010.

[67] R. Kumar and S. C. Kaushik, "Performance evaluation of green roof and shading for thermal protection of buildings," Building and Environment, vol. 40, no. 11, pp. 1505-1511, 2005.

[68] B. Hong, B. Lin, L. Hu, and S. Li, "Optimal tree design for sunshine and ventilation in residential district using geometrical models and numerical simulation," Building Simulation, vol. 4, no. 4, pp. 351-363, 2011.

[69] M. Zennaro, A. Bagula, D. Gascon, and A. Bielsa, "Planning and deploying long distance wireless sensor networks: the integration of simulation and experimentation," in Proceedings of the 9th International Conference (ADHOC-NOW'10), pp. 191204, Edmonton, Canada, August 2010.

[70] D. E. Cook, P. A. Strong, S. A. Garrett, and R. E. Marshall, "A small unmanned aerial system (UAS) for coastal atmospheric research: preliminary results from New Zealand," Journal of the Royal Society of New Zealand, vol. 43, no. 2, pp. 108-115, 2013.

[71] P. G. Tuohy, L. B. McElroy, and C. Johnstone, "Thermal mass, insulation and ventilation in sustainable housing-an investigation across climate and occupancy," in Proceedings of the 9th International IBPSA Conference on Building Simulation (BS '05), pp. 1253-1260, Montreal, Canada, August 2005.

[72] F. Aldawi, F. Alam, I. Khan, and M. Alghamdi, "Effect of climates and building materials on house wall thermal performance," Procedia Engineering, vol. 56, pp. 661-666, 2013.

[73] A. Inagaki, M. Kanda, S. Onomura, and H. Kumemura, "Thermal image velocimetry," Boundary-Layer Meteorology, vol. 149, no. 1, pp. 1-18, 2013.

[74] K. J. Allwine, J. H. Shinn, G. E. Streit, K. L. Clawson, and M. Brown, "Overview of Urban 2000: a multiscale field study of dispersion through an urban environment," Bulletin of the American Meteorological Society, vol. 83, no. 4, pp. 521-536, 2002.

[75] J. Kleissl, R. E. Honrath, M. P. Dziobak et al., "Occurrence of upslope flows at the Pico mountaintop observatory: a case study of orographic flows on a small, volcanic island," Journal of Geophysical Research D: Atmospheres, vol. 112, no. 10, Article ID D10S35, 2007.

[76] P. Sedlák, M. Aubinet, B. Heinesch et al., "Night-time airflow in a forest canopy near a mountain crest," Agricultural and Forest Meteorology, vol. 150, no. 5, pp. 736-744, 2010.

[77] C. Feigenwinter, L. Montagnani, and M. Aubinet, "Plot-scale vertical and horizontal transport of $\mathrm{CO}_{2}$ modified by a persistent slope wind system in and above an alpine forest," Agricultural and Forest Meteorology, vol. 150, no. 5, pp. 665-673, 2010.

[78] L. S. Savage, S. Zhong, W. Q. Yao, T. Horst, and W. O. Brown, "A regional-scale downslope wind observed during the 
METCRAX Experiment in Northern Arizona," in Proceedings of the 18th Symposium on Boundary Layer and Turbulence, Stockholm, Sweden, June 2008.

[79] J. Allegrini, V. Dorer, and J. Carmeliet, "Wind tunnel measurements of buoyant flows in street canyons," Building and Environment, vol. 59, pp. 315-326, 2013. 

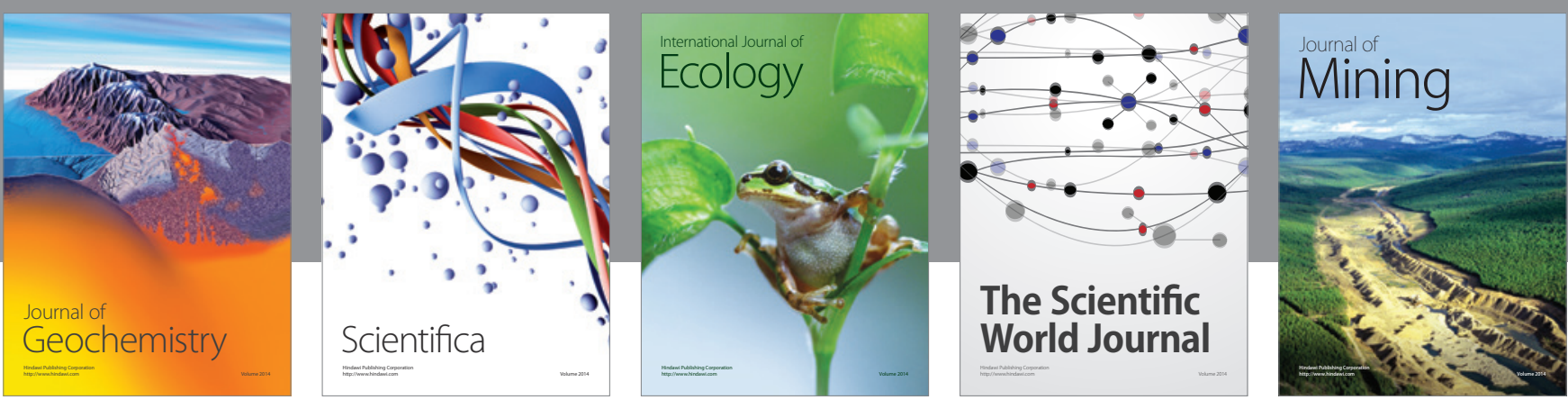

The Scientific World Journal
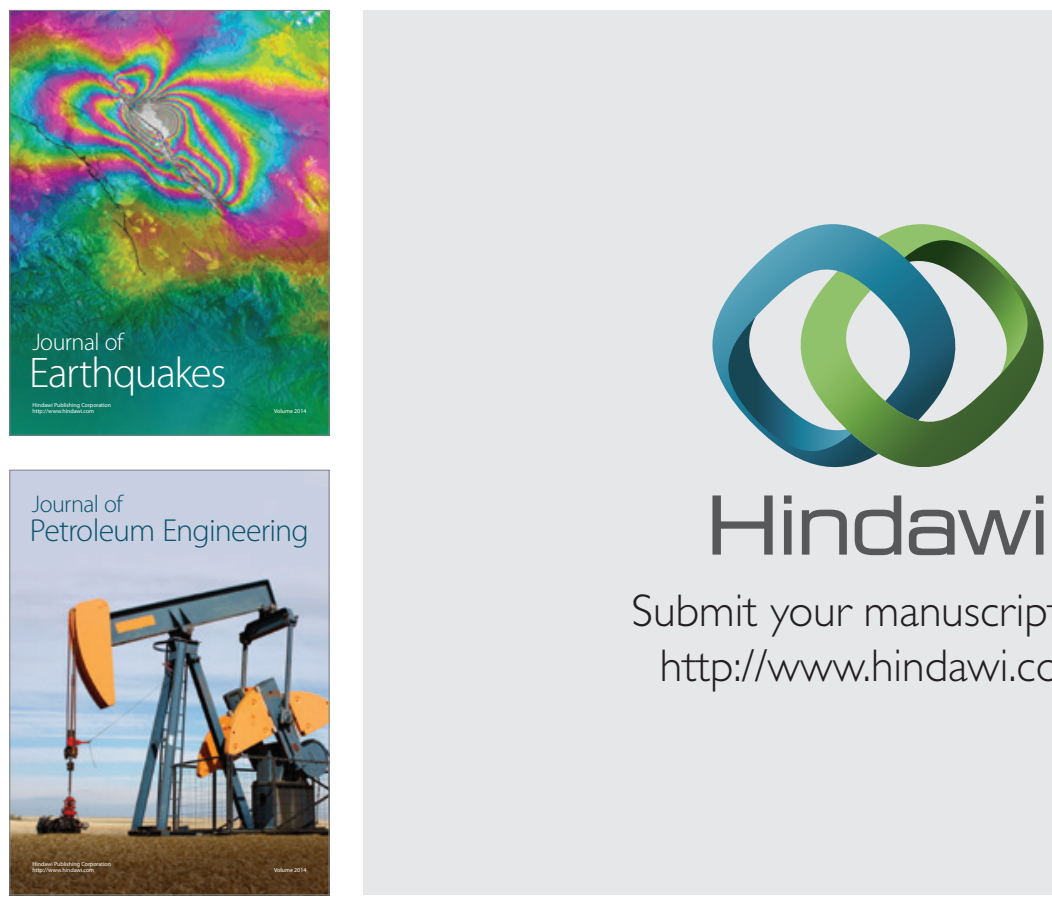

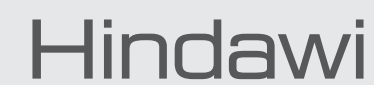

Submit your manuscripts at

http://www.hindawi.com
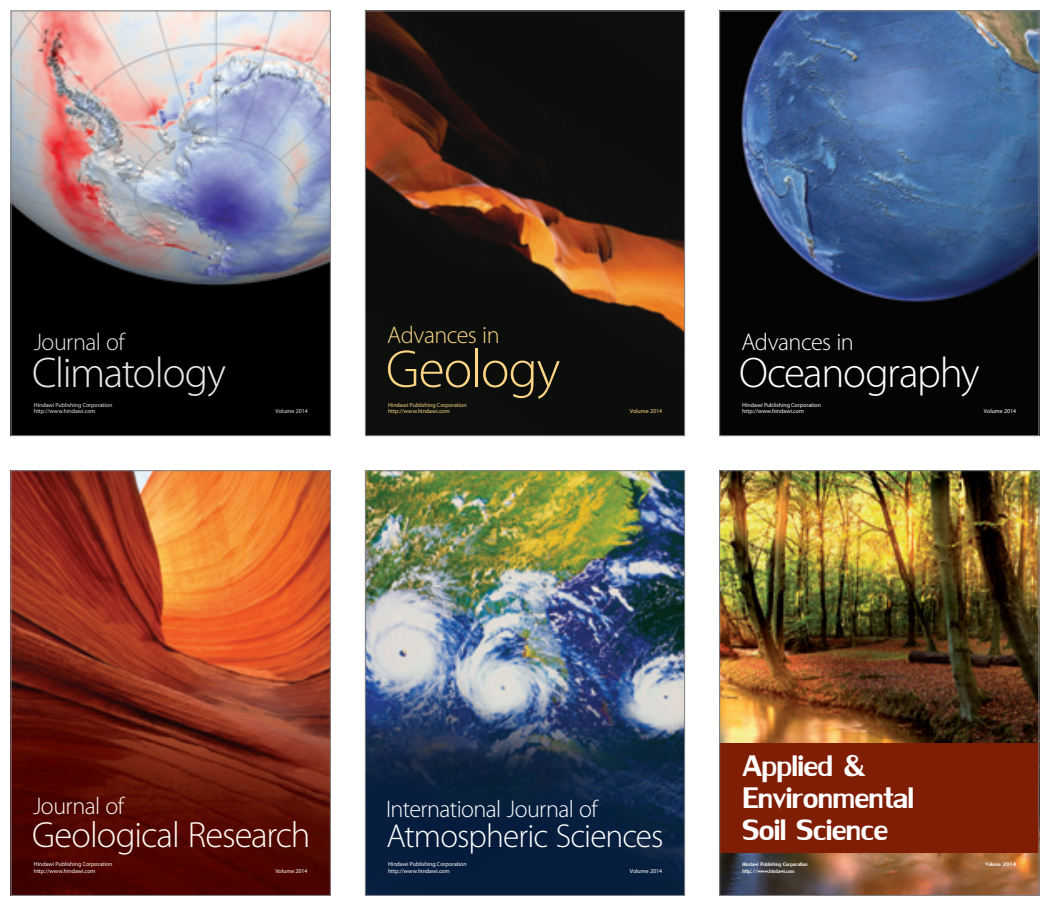
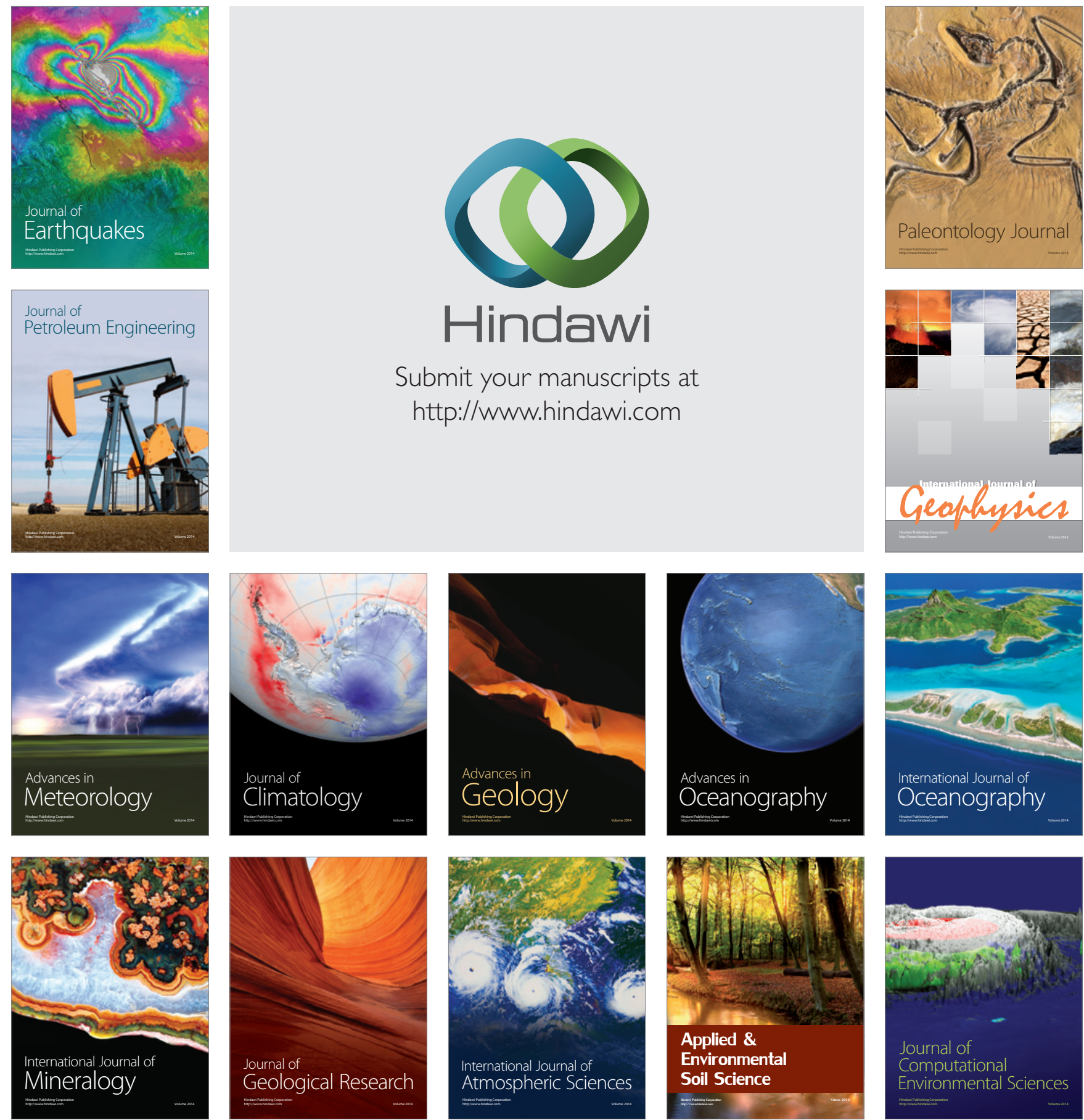